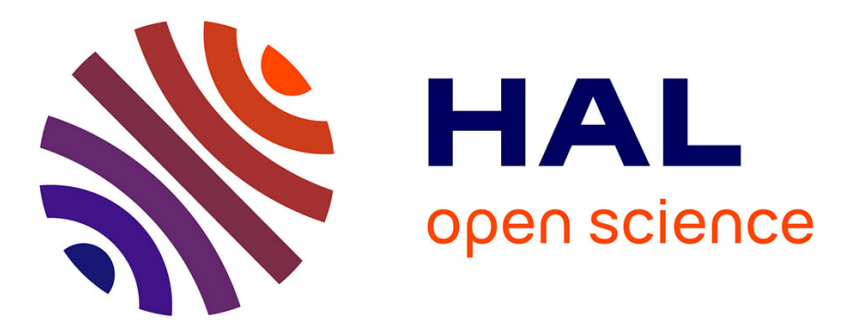

\title{
COMT Val158Met polymorphism and socioeconomic status interact to predict attention deficit/hyperactivity problems in children aged 10-14
}

Maria Nobile, Marianna Rusconi, Monica Bellina, Cecilia Marino, Roberto

Giorda, Ombretta Carlet, Laura Vanzin, Massimo Molteni, Marco Battaglia

\section{To cite this version:}

Maria Nobile, Marianna Rusconi, Monica Bellina, Cecilia Marino, Roberto Giorda, et al.. COMT Val158Met polymorphism and socioeconomic status interact to predict attention deficit/hyperactivity problems in children aged 10-14. European Child and Adolescent Psychiatry, 2009, 19 (7), pp.549-557. 10.1007/s00787-009-0080-1 . hal-00540583

\section{HAL Id: hal-00540583 https://hal.science/hal-00540583}

Submitted on 28 Nov 2010

HAL is a multi-disciplinary open access archive for the deposit and dissemination of scientific research documents, whether they are published or not. The documents may come from teaching and research institutions in France or abroad, or from public or private research centers.
L'archive ouverte pluridisciplinaire HAL, est destinée au dépôt et à la diffusion de documents scientifiques de niveau recherche, publiés ou non, émanant des établissements d'enseignement et de recherche français ou étrangers, des laboratoires publics ou privés. 


\title{
COMT Val158Met polymorphism and socioeconomic status interact to predict attention deficit/hyperactivity problems in children aged 10-14
}

\author{
Maria Nobile $\cdot$ Marianna Rusconi $\cdot$ Monica Bellina \\ Cecilia Marino • Roberto Giorda • Ombretta Carlet • \\ Laura Vanzin · Massimo Molteni · Marco Battaglia
}

Received: 14 November 2008/ Accepted: 10 November 2009/Published online: 28 November 2009

(C) Springer-Verlag 2009

\begin{abstract}
The functional Val158Met COMT polymorphism appears to affect a host of behaviours mediated by the pre-frontal cortex, and has been found associated to the risk for disruptive behaviours including ADHD. Parental socioeconomic status (SES) has also been reported as a predictor for the same childhood disorders. In a general population sample of 575 Italian pre-adolescents aged 10 14, we examined the association of the functional Val158Met COMT polymorphism and SES—both as linear and interactive effects-with oppositional defiant problems, conduct problems, and attention deficit/hyperactivity problems, as defined by the newly established Child Behaviour Check-List/6-18 DSM oriented scales. Multivariate- and subsequent univariate-analysis of covariance showed a significant association of COMT $\times$ SES
\end{abstract}

M. Nobile $(\bowtie) \cdot$ M. Bellina · C. Marino · L. Vanzin .

M. Molteni · M. Battaglia

Department of Child Psychiatry,

Eugenio Medea Scientific Institute,

via Don Luigi Monza 20, 23842 Bosisio Parini (LC), Italy

e-mail: mnobile@bp.lnf.it; maria.nobile@bp.lnf.it

M. Rusconi - R. Giorda

Molecular Biology Laboratory, Eugenio Medea Scientific

Institute, Bosisio Parini, Italy

C. Marino

Department of Psychiatry, CRULRG, Laval University,

Quebec G1K7P4, Canada

O. Carlet

Department of Child Psychiatry,

Eugenio Medea Scientific Institute, Conegliano, Italy

M. Battaglia

Centre for the Study of Behavioural Plasticity,

Vita-Salute San Raffaele University, 20127 Milan, Italy interaction with CBCL 6/18 DOS attention deficit/hyperactivity problems $(p=0.004)$, and revealed higher scores among those children with Val/Val COMT genotype who belonged to low-SES families. We also found a significant association of SES with attention deficit/hyperactivity problems and conduct problems DOS ( $p=0.04$ and 0.01, respectively). Our data are consistent with a bulk of recent literature suggesting a role of environmental factors in moderating the contribution of specific genetic polymorphisms to human variability in ADHD. While future investigations will refine and better clarify which specific environmental and genetic mechanisms are at work in influencing the individual risk to ADHD in pre-adolescence, these data may contribute to identify/prevent the risk for ADHD problems in childhood.

Keywords COMT polymorphism - SES - ADHD · $\mathrm{CBCL} \cdot$ Gene-environment interaction

\section{Introduction}

One of the features which render the dopamine system in the pre-frontal cortex different from other brain regions is the significantly lower concentration of the dopamine transporter protein [15]. Such relative lack of dopamine transporter makes the pre-frontal cortex more dependent on other mechanisms, like the catechol- $O$-methyltransferase (COMT) enzyme, to terminate the action of released dopamine. Consistent with this view, the COMT enzyme accounts for more than $60 \%$ of dopamine degradation in the pre-frontal cortex, but for less than $15 \%$ of dopamine degradation in the striatum [28]. As a consequence, variations within the COMT gene, which encodes for the COMT enzyme, would be expected to affect the pre-frontal 
cortex's function much more dramatically than other brain regions (such as the striatum), the function of which could be relatively unaffected by the action of this enzyme.

The COMT gene (located within the q11 region of chromosome 22) contains a single G-to-A base-pair missense variant. This polymorphism translates into a substitution of methionine for valine at codon 158 (Val158Met), with the enzyme containing Met158 having one-third to one-fourth of the activity of the Val158 enzyme $[36,49]$ in degrading dopamine, epinephrine, and norepinephrine.

Indeed, several investigations including an 'oddball' task-generated P300 waveform study of healthy controls and patients with schizophrenia [24] suggest the presence of increased dopaminergic cortical signalling, enhanced signal/noise ratio, and optimized cortical activity, conferred by the Met allele, during processing tasks of different nature [18, 25, 39, 47]. Two brain imaging studies of healthy adults showed an influence of the COMT Val158Met genotype on task-related brain activation. One study [7] showed that the Met allele confers better cognitive performance and optimal cingulate activation during visual cognitive control tasks, while another study [47] showed that the Met allele is associated with higher prefrontal, limbic, and cortical sensory (fusiform gyrus and inferior parietal lobule) activation during the act of processing social stimuli.

The COMT genotype was also demonstrated to impact on cognitive functions that depend on pre-frontal dopaminergic activity in children and adolescents [15, 53], and the Met allele predicted promptness as indexed by the ERP N170 waveform latency in normally developing children during a task of implicit face expressions' processing [4].

The possible effect of COMT genotype in developmental psychopathology was investigated in ADHD, with diverging findings: some studies reported evidence of an association, while others did not (for a review [20]), and two recent meta-analyses could not confirm a role for COMT Val158Met in the aetiology of ADHD [12, 20]. Indeed, inasmuch as externalizing children appear to share a feature of suboptimal development of inhibitory control and self-regulation [6], the investigation of the possible effects of the COMT genotype [15] upon childhood and adolescent psychopathology could -and perhaps should- be extended to disruptive behaviours beyond ADHD.

More recently, the COMT gene was also associated with phenotypic variation among children with ADHD, suggesting that Val/Val homozygotes had more symptoms of conduct disorder, were more aggressive, and were more likely to be convicted of criminal offences compared with methionine carriers [9], while Thapar et al. [51] reported that COMT gene variant and low birth weight predict early onset of antisocial behaviour in children with ADHD. This data, however, has not been confirmed [46].
In sum, while data regarding the influences of the COMT gene upon cognitive functions and the pre-frontal dopamine activity are quite consistent across different life periods $[15,53]$, the evidence for an influence of the COMT gene upon childhood behavioural disorders is less robust. This could be due to the inherent complexity of the mechanisms that underlie the influence of the COMT gene upon childhood psychopathology, such as gene-environment interplay effects, and/or the fact that the COMT gene could be operant only for some distinct subtypes of externalizing disorders. This would conceivable, since childhood behavioural disorders are heterogeneous, complex phenotypes that result from genetic and environmental causal factors. The child's genotype may exert its effects by variation in response to the environment (gene-environment interplay) or by shaping environmental exposures (gene-environment co-variance) [45], and a variety of often-uncontrolled environmental factors (both familyshared and idiosyncratic, see for e.g. $[8,10,27,38,45])$ have been found to mediate the genetic influence in the expression of liability to childhood psychopathology.

Parental socioeconomic status (SES) could be one such environmental factor. Although limited by the fact of being a generic, broad, distal risk variable which is measured at a family-wide rather than at a child-specific level, SES is a powerful predictor of childhood psychopathology, including delinquent and aggressive syndromes [3, 52], and ADHD [5].

Low SES may contribute to these psychopathologies either directly or indirectly, through negative effects onto more proximal child-specific factors, such as parenting [14] or exposure to trauma [19].

Recently Lasky-Su et al. [33] suggested that low SES may not only exert a direct influence over the risk of developing ADHD, but also, SES may act as a mediator of the effect of specific genes to increase or decrease the likelihood of ADHD. For example, low level of SES is associated with decreased income, which likely results in decreased health care. Reduced health care often results in a higher incidence of low birth weight, which is in turn associated with a threefold increase in ADHD incidence [40].

In spite of the potential interest in investigating how specified environmental moderators and candidate genes influence biological systems and behaviour, no study has so far analysed the possible conjoint impact of SES and COMT polymorphism upon childhood externalizing behaviours.

Given the potential role of COMT and SES on influencing more than one externalizing psychopathological traits (hyperactivity, aggressiveness, antisocial behaviour, conduct problems, etc.) we took into account a broad 'spectrum' of behavioural disorders as collected by the 
Child Behaviour CheckList 6/18 [2], namely attention deficit/hyperactivity problems, oppositional defiant problems, and conduct problems DSM oriented scale (DOS).

Compared to the classic CBCL 6/18 empirical subscales, the newly established CBCL 6/18 DSM-Oriented Scales (DOS) system have higher heritability and simpler causal structure, in that the phenotypic variance can be satisfactorily explained by additive genetic and unique environmental factors only [48].

Furthermore, the CBCL 6/18 DOSs appear to correspond well to the current DSM-IV diagnoses [30].

In the present study we examined the association of a functional COMT polymorphism (which potentially affects behaviours mediated by the pre-frontal cortex) and a societal moderator (parental SES), and of their interactions, with CBCL 6/18 oppositional defiant problems, conduct problems and attention deficit/hyperactivity problems DOS, in a general population sample of Italian preadolescents.

\section{Methods}

The participants in this study were subjects involved in two epidemiological studies of mental health in youth. Subjects from sample $1(n=446)$ were recruited by our group as a collaborating centre of the Italian Project on pre-adolescent mental health (the PrISMA project-Progetto Italiano Salute Mentale Adolescenti) [22].

The PrISMA project was designed to estimate the prevalence of behavioural problems using the CBCL/6-18 [2] scale in a National probability sample of children aged 10-14 years living and attending secondary school in 7 medium-to-large Italian urban areas (Milan, Rimini, Lecco and Conegliano located in the north of Italy, Rome and Pisa in the centre and Cagliari in the south of the country) and had an overall participation rate of $61 \%$ of the eligible subjects $[22,23]$. The mean values of the CBCL/6-18 subscales of children assessed in the PrISMA project did not differ significantly across these seven different urban areas (data available from authors upon request) and were comparable to those obtained in previous epidemiological studies of the CBCL scale in Italy [21]. Amongst the seven PrISMA participating units, two (one based in Bosisio Parini near Lecco, and the other in Conegliano) have interests in behavioural genetics and the technology for DNA collection and molecular genetic analyses. Therefore, for the PrISMA children living in Lecco and Conegliano, in addition to providing demographic and psychometric information, we also invited the participants to DNA collection, which was allowed by parental written informed consent for 446 out of 1,211 (37\%) eligible children.
Subjects from sample 2 belong to a relatively small suburban community (Ponte Lambro-PL, inhabitants $4,065)$ currently involved in an ongoing longitudinal study of emotional and behavioural problems in childhood with the CBCL/6-18 [2] and simultaneous DNA collection. The DNA of 172 out of 317 (54\%) eligible children aged 10-14 living in PL was collected after parental written informed consent.

More than $95 \%$ of participating children were Caucasian and of Italian ancestry. Although attending the same school grade, children in the PrISMA sample were slightly older than children in the PL sample, due to a modest difference in the timing of recruitment of the two samples (winter for the PrISMA sample and fall for the PL sample [41, 42]).

The PL and PrISMA samples have no overlapping subjects. Since the inclusion (age between 10 and 14 years, parental written informed consent) and exclusion criteria (certification of mental handicap, which was present in $0.3 \%$ of eligible participants) and the psychometric instrument (parental assessments of children behaviour through the CBCL/6-18) were the same for the PrISMA and the PL samples, after controlling for the homogeneity of demographic and behavioural variables, as in two previous studies regarding externalizing behaviour and affective problems [41, 42], for the present study we pooled together subjects of both epidemiological samples to increase the statistical power.

\section{Procedures}

The study protocols were approved by the 'Eugenio Medea' Scientific Institute Ethical Committee. Parents' written informed consent was obtained for all participants.

\section{Behavioural assessment}

The CBCL/6-18 [2] is an empirically based checklist of social competence and behavioural problems filled out by parents of children and adolescents aged 6-18 years. According to the Achenbach System of Empirically Based Assessment (ASEBA) CBCL/6-18 items can be scored to obtain the following DSM-oriented scales (DOS): affective problems, anxiety problems, somatic problems, attention deficit/hyperactivity problems, oppositional defiant problems, and conduct problems (see Table 1 for items included in attention deficit/hyperactivity problems, oppositional defiant problems and conduct problems DOS).

Although the DOSs are not directly equivalent to any clinical diagnosis, they satisfactorily predict DSM-IV diagnoses [30]. Recent twin multivariate genetic epidemiological analyses in the Italian general population showed that compared with the classic CBCL/6-18 empirical subscales, the DOSs have higher heritability (lowest 0.56 and 
Table 1 CBCL/6-18 items for attention deficit/hyperactivity problems, oppositional defiant problems, and conduct problems DOS

\begin{tabular}{lll}
\hline Attention deficit/hyperactivity problems & Oppositional defiant problems & Conduct problems \\
\hline Fails to finish things he/she starts & Argues a lot & Cruel to animals \\
Can't concentrate, can't pay attention for long & Disobedient at home & Cruelty, bullying, or meanness to others \\
Can't sit still, restless, or hyperactive & Disobedient at school & Destroys things belonging to his/her family or others \\
Impulsive or acts without thinking & Stubborn, sullen, or irritable & Does not seem to feel guilty after misbehaving \\
Inattentive or easily distracted & Temper tantrums or hot temper & Breaks rules at home, school, or elsewhere \\
Talks too much & & Gets in many fights \\
Unusually loud & & Hangs around with others who get in trouble \\
& & Lying or cheating \\
& & Physically attacks people \\
& & Runs away from home \\
& Sets fires \\
& Steals at home \\
& Steals outside the home \\
& Swearing or obscene language \\
& Threatens people \\
& Truancy, skips school \\
\hline
\end{tabular}

0.61 for attention deficit/hyperactivity problems and oppositional defiant problems; highest 0.71 for conduct problems), and simpler causal structure, in that the phenotypic variance is satisfactorily explained by additive genetic and unique environmental factors only [48]. Moreover, the covariation of DOS scales can best be attributed to one common genetic factor and to two idiosyncratic environmental factors, each loading differently on the internalizing (anxiety and affective problems) and the externalizing (attention-deficit/hyperactivity, oppositional defiant, and conduct problems).

We used parental employment as a measure of SES coded according to the Hollingshead 9-point scale for parental occupation [26]. A score of 1-9 was assigned to each parental job; when both parents were employed, the highest of the two scores was used. Because low SES, in contrast to medium and high SES, has been identified as a specific risk factor for a host of externalized behaviours, such as hyperactive, impulsive, aggressive, and rulebreaking behaviour [3, 5, 16, 29, 35, 52] we split SES into two classes of risk: low SES 1-3 (mean: $2.88 \pm 0.35$ ) and medium to high SES 4-9 $(6.46 \pm 1.74)$.

\section{DNA collection and extraction}

Genomic DNA was extracted from mouthwash samples collected in 4\% sucrose using the DNAzol Genomic DNA Isolation reagent (Molecular Research Center, Cincinnati, $\mathrm{OH})$. We determined the subject's COMT Val158Met genotype using the $5^{\prime}$-exonuclease Taqman assay [11]. Subjects with known genotype, previously typed by sequencing were used as positive controls. The Taqman primers, probes, and reagents were purchased from Applied Biosystems (Monza, Italy). The assays were performed and analysed on a 9700HT Sequence Detection System (Applied Biosystems).

\section{Statistical analyses}

Previous controls for biases performed upon demographic and behavioural variables showed no, or only modestly significant differences in behavioural variables in children belonging to families who agreed versus those belonging to families who did not agree to participate in the genetic study [41, 42]. Moreover, there were no significant differences owing to SES $(t=-0.72, p=0.47)$ or age ( $t=-1.34, p=0.18$ ) between PrISMA children belonging to families who agreed versus those belonging to families who did not agree to participate in the genetic study [41].

As more than $95 \%$ of participating children were Caucasian, to have a more homogeneous sample non-Caucasian children were not included in genetic analyses.

According to the Val158Met polymorphism the COMT genotype was classified as $\mathrm{Val} / \mathrm{Val}$, Val/Met, and Met/Met.

We preliminarily analysed the distribution of COMT genotypes across children's genders, and SES classes, and found no significant associations $\left(\chi^{2}=0.825\right.$, $d f=2, p=0.662$, and $\chi^{2}=1.777, d f=2, p=0.411$, respectively).

The distributions of the CBCL DOS scores were squareroot transformed to attenuate deviations from normality, 
which led to acceptable kurtosis ( $\min -0.533$, max 0.628), and skewness ( $\min -0.569$, $\max 0.647$ ) values.

The COMT genotype and the SES were entered simultaneously as independent variables, while the CBCL/6-18 attention-deficit/hyperactivity, oppositional defiant, and conduct problems DOSs were the dependent variables in the multivariate -and in the subsequent univariate-analysis of covariance (ANcOVA), with gender and age as covariates.

All analyses were performed using the Statsoft Statistical package (Version 6.0, 1997).

\section{Results}

Table 2 shows the demographic and behavioural variables in the two original epidemiological samples and in the combined sample.

As typically observed in epidemiological samples [13, 21, 31, 32, 34, 37, 43, 44, 50], oppositional defiant DOS, conduct problems DOS, and attention deficit/hyperactivity problems DOS scores were higher in boys than in girls $(F=10.540, \quad p=0.001 ; \quad F=26.266, \quad p<0.001 ; \quad$ and $F=18.622, p<0.001$, respectively); there were no significant differences between the PrISMA and the PL subsamples for all DOS scores.

COMT genotyping was successful for 575 subjects with complete sociodemographic and behavioural data. The genotype frequencies in the total sample were: $\mathrm{Val} / \mathrm{Val}$ 29.4\%, Val/Met $48.0 \%$, Met/Met $22.6 \%$ and the allele frequencies were Val $53.4 \%$ and Met $46.6 \%$. The COMT polymorphism was in Hardy-Weinberg equilibrium both in PrISMA and in PL subsamples $\left(\chi^{2}=0.066, p=0.963\right.$ and $\chi^{2}=2.023, p=0.155$, respectively) and in the total sample $\left(\chi^{2}=0.727, p=0.39\right)$.

COMT genotype frequencies were even across gender $\left(\chi^{2}=0.825, d f=2, p=0.662\right)$, across the two SES categories $\left(\chi^{2}=1.777, d f=2, p=0.411\right)$, and across the PrISMA and the PL subsamples $\left(\chi^{2}=4.636, p=0.098\right)$.
Table 3 shows the square-root transformed CBCL DOS scores according to COMT genotype and SES. The twoway MANcOVA-with sex and age as covariatesrevealed a significant COMT $\times$ SES interaction (Rao's $R=2.735, d f=6.1132, p=0.012)$, a trend for SES (Rao's $R=2.547, d f=3.565, p=0.055$ ), but no significant association of COMT genotype (Rao's $R=1.005$, $d f=6.1132, p=0.420$ ).

Subsequent ANcOVAs revealed a significant association of SES with attention deficit/hyperactivity problems DOS $(p=0.040)$ and conduct problems DOS $(p=0.010)$, and a COMT $\times$ SES interaction with attention deficit/hyperactivity problems DOS $(p=0.004)$.

Post hoc analyses showed significantly higher scores on attention deficit/hyperactivity problems DOS among children of low SES with the Val/Val genotype, compared to medium + high SES children with Val/Val and Met/Met genotypes (respectively, Tukey HSD $p=0.002$ and $0.025)$. There was only a statistical trend towards significance when we compared post hoc the attention deficit/ hyperactivity problem DOS scores of low SES children with the $\mathrm{Val} / \mathrm{Val}$ genotype to the scores of children with medium + high SES and the Val/Met genotype $(p=0.063$ by Tukey HSD; see Fig. 1).

We also repeated analyses with non-transformed dependent variables. The two way MANcOVA revealed a significant association of SES (Rao's $R=2.767$, $d f=3.565, p=0.041)$, and a trend for COMT $\times$ SES interaction (Rao's $R=1.943, d f=6.1130, p=0.071$ ). Subsequent ANcOVAs confirmed a significant association of SES with attention deficit/hyperactivity problems DOS $(p=0.009)$ and conduct problems DOS $(p=0.022)$, and of COMT $\times$ SES interaction with attention/deficit hyperactivity problems DOS $(p=0.042)$. Post-hoc analyses substantially confirmed significantly higher scores among children of low SES with the Val/Val genotype, compared to medium + high SES children with $\mathrm{Val} / \mathrm{Val}$ and $\mathrm{Val} / \mathrm{Met}$ genotype (respectively, Tukey HSD $p=0.007$ and 0.022 ).

Table 2 Demographic and behavioural variables (raw data) in the two original epidemiological samples and in the combined sample

\begin{tabular}{|c|c|c|c|c|c|c|}
\hline & \multicolumn{2}{|c|}{ PrISMA $(n=446)$} & \multicolumn{2}{|l|}{$\mathrm{PL}(n=172)$} & \multicolumn{2}{|c|}{ Combined sample $(n=618)$} \\
\hline & Boys $(n=235)$ & Girls $(n=211)$ & Boys $(n=83)$ & Girls $(n=89)$ & Boys $(n=318)$ & Girls $(n=300)$ \\
\hline Age $($ mean $\pm \mathrm{SD})$ & $12.12 \pm 0.92$ & $12.16 \pm 0.89$ & $12.07 \pm 0.81$ & $11.91 \pm 0.834$ & $12.11 \pm 0.89$ & $12.08 \pm 0.88$ \\
\hline Low SES (\%) & $11.2 \%$ & $15.1 \%$ & $18.7 \%$ & $17.9 \%$ & $13.2 \%$ & $15.9 \%$ \\
\hline $\mathrm{SES}($ mean $\pm \mathrm{SD})$ & $5.96 \pm 1.94$ & $6.07 \pm 2.15$ & $5.62 \pm 2.20$ & $5.52 \pm 1.93$ & $5.87 \pm 2.02$ & $5.92 \pm 2.10$ \\
\hline \multicolumn{7}{|l|}{ DOS scores (mean $\pm \mathrm{SD})$} \\
\hline Attention deficit/hyperactivity problems & $3.93 \pm 2.83$ & $2.96 \pm 2.83$ & $3.77 \pm 3.16$ & $2.55 \pm 2.40$ & $3.89 \pm 2.91$ & $2.84 \pm 2.71$ \\
\hline Oppositional defiant problems & $2.54 \pm 1.71$ & $2.06 \pm 1.72$ & $2.72 \pm 1.95$ & $2.08 \pm 1.45$ & $2.59 \pm 1.77$ & $2.06 \pm 1.64$ \\
\hline Conduct problems & $1.55 \pm 2.11$ & $0.93 \pm 1.50$ & $2.02 \pm 2.72$ & $0.95 \pm 1.51$ & $1.68 \pm 2.29$ & $0.94 \pm 1.50$ \\
\hline
\end{tabular}


Table 3 Behavioural variables (square-root adjusted) grouped according to COMT genotype and SES

\begin{tabular}{|c|c|c|c|c|c|}
\hline \multirow[t]{2}{*}{ SES } & \multicolumn{3}{|l|}{ COMT genotype } & \multicolumn{2}{|c|}{$\mathrm{COMT} \times \mathrm{SES}$} \\
\hline & $\mathrm{Val} / \mathrm{Val}(n)$ & Val/Met $(n)$ & Met/Met $(n)$ & $F$ & $p$ \\
\hline \multicolumn{6}{|c|}{ Attention deficit/hyperactivity problems } \\
\hline Low & $2.09 \pm 0.63(31)$ & $1.66 \pm 1.12(43)$ & $1.46 \pm 1.05(17)$ & 5.693 & 0.004 \\
\hline Mid + high & $1.42 \pm 0.93(138)$ & $1.62 \pm 0.91(233)$ & $1.54 \pm 0.82(113)$ & & \\
\hline \multicolumn{6}{|c|}{ Oppositional defiant problems } \\
\hline Low & $1.55 \pm 0.48(31)$ & $1.46 \pm 0.74(43)$ & $1.32 \pm 0.84(17)$ & 0.365 & 0.694 \\
\hline Mid + high & $1.40 \pm 0.71(138)$ & $1.32 \pm 0.72(233)$ & $1.33 \pm 0.61(113)$ & & \\
\hline \multicolumn{6}{|c|}{ Conduct problems } \\
\hline Low & $1.00 \pm 0.87(31)$ & $0.91 \pm 1.00$ & $1.00 \pm 0.82(17)$ & 0.461 & 0.631 \\
\hline Mid + high & $0.72 \pm 0.85(138)$ & $0.74 \pm 0.82(233)$ & $0.71 \pm 0.81$ & & \\
\hline
\end{tabular}

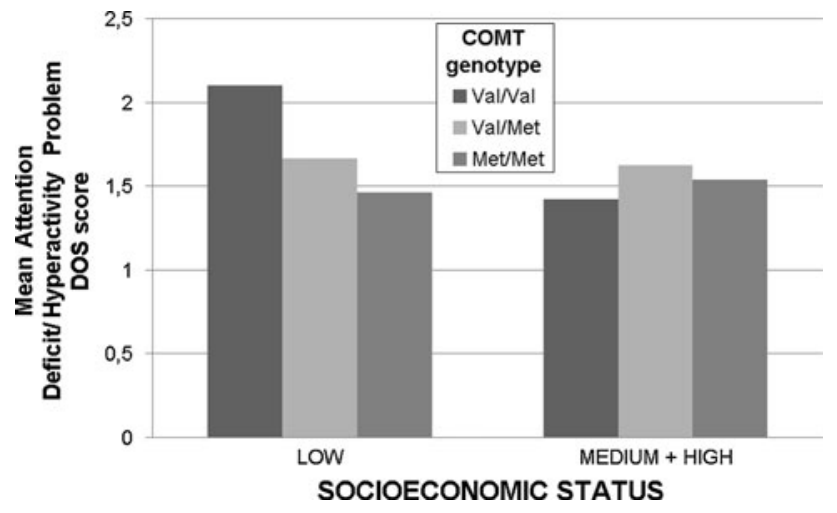

Fig. 1 CBCL 6/18 attention deficit/hyperactivity problems DOS (square-root adjusted) according to socioeconomic status (SES) $\times-$ COMT genotype

When we analysed the association of COMT genotype with oppositional defiant and conduct problems in those children who scored high on the attention deficit/hyperactivity problems DOS scale $\left(>90^{\circ}\right.$ percentile, $\left.n=50\right)$, results remained non-significant $(p=0.155$ and 0.383 , respectively).

\section{Discussion}

This is the first study taking conjunctly into account the association of the COMT Val158Met polymorphism, and a societal moderator, namely SES, with several behavioural problems in a general population sample of children aged 10-14. Our main findings show that low-SES and the Val/ Val COMT genotype interact in heightening the probability of having attention deficit/hyperactivity problems.

Inasmuch as our findings suggest that in presence of adverse environmental factors, subjects with the $\mathrm{Val} / \mathrm{Val}$ COMT genotype are more susceptible to ADHD problems, we are in broad agreement with the findings by Thapar et al. [51], who showed an interactional effect of the same genotype with another major environmental risk factor, namely low birth weight, in influencing simultaneously conduct disorder and ADHD. Somewhat similarly, Lasky$\mathrm{Su}$ et al. [33] reported that SES moderates the effect of the BDNF gene upon the number of ADHD symptoms.

We also found a significant association of SES with attention deficit/hyperactivity problems and conduct problems. This result is in agreement with previous studies investigating the influence of SES on externalizing problems [3, 52], including ADHD [5].

We did not find a general linear association of COMT genotype with the behavioural problems investigated in this study. This could be partly due to the use of MANcOVA; while this type of analysis can protect against Type I errors, it yields a loss of power (basically, implying the loss of one degree of freedom for each dependent variable added to the list), which may become important with a sample size of 600 .

On the other hand, the lack of a direct association between COMT Val158Met polymorphism and ADHD symptoms is consistent with meta-analytic negative results of the association between COMT and ADHD [12, 20].

We did not find an association between COMT gene per se, or in interaction, with SES and oppositional defiant or conduct problems. These results are somehow in agreement with data published by Caspi et al. [9] who did not find an association between the COMT Val158Met variant and antisocial behaviour in the general population but only within a subgroup of subjects diagnosed with ADHD.

In contrast to Caspi et al. [9], however, we did not find an association with the COMT Val158Met variant and conduct problems in children who scored high on the attention deficit/hyperactivity problems DOS scale in our sample. However, compared with the three independent samples in the Caspi et al. study, it should be considered that we had a much smaller sample size, no interview-based direct assessment, and smaller prevalence of conduct problems [23]. Nonetheless, our findings of an association between 
SES $\times$ COMT genotype interaction and attention deficit/ hyperactivity problems, require cautious considerations.

The SES is a complex construct that incorporates many measures, including education or income, and is also indirectly related to many other variables, some of which may be partially genetic in origin. Therefore, the possibility remains that what we have interpreted as a gene-by-environment interaction could in fact be a gene-by-gene interaction.

Although this study is based on a genetically homogeneous sample, the stratification bias typical of populationbased association studies is still possible, and our results need independent replication in extended family-based studies. Moreover, since our population is primarily Caucasian, the implications of our results may not be extendable to other ethnic groups with different allele frequencies or environmental/social factors, which may impinge differently upon externalizing behaviours.

Another limitation of this study is the use of parent-rated CBCL questionnaires only. Although parental reports are often used for assessing problem behaviours and psychiatric disorders in children, and externalized behaviours typically provide good replicability across different observers [1, 13], direct assessments through direct interviews are by definition more informative and reliable.

Furthermore, there is now a clear contrast between the enthusiasm elicited by behavioural studies which suggest interactions between identified candidate genes and specific environmental factors, and the sobriety induced by simulated data analyses studies, such as those failing to find significant $\mathrm{G} \times \mathrm{E}$ interaction for liability to dichotomously defined depression or antisocial disorder [17]. Such divergence of results further suggests prudence, since there might be risks of oversimplification, and inflation of significance in virtually any analysis of variance focused on a limited pool of polymorphisms and environmental risk factors for a single/few behavioural variable(s).

\section{Conclusion}

We report a significant interaction between the COMT Val158Met polymorphism and low SES associated with pre-adolescent attention deficit/hyperactivity problems. This data is consistent with the recent literature [33, 51] suggesting a role for environmental factors in moderating the contribution of specific genetic polymorphisms to human variability in ADHD.

While future investigations may better clarify which specific environmental and genetic mechanisms are at work in influencing the individual risk to ADHD in pre-adolescence, these data may contribute to identify/prevent risk for more severe pattern of ADHD problems in childhood.
Acknowledgments This study was supported by Grant R.F.20022003 N. 182 from the Italian Ministry of Health.

\section{References}

1. Achenbach TM, McConaughy SH, Howell CT (1987) Child/ adolescent behavioral and emotional problems: Implications of cross-informant correlations for situation specificity. Psychol Bull 101:213-232

2. Achenbach TM, Rescorla LA (2001) Manual for the ASEBA school-age forms and profiles. University of Vermont, Department of Psychiatry, Burlington

3. Barry TD, Dunlap ST, Cotten SJ, Lochman JE, Wells KC (2005) The influence of maternal stress and distress on disruptive behavior problems in boys. J Am Acad Child Adolesc Psychiatry 44:265-273

4. Battaglia M, Zanoni A, Giorda R, Pozzoli U, Citterio A, Beri S, Ogliari A, Nobile M, Marino C, Molteni M (2007) Effect of the catechol-O-methyltransferase val(158)met genotype on children's early phases of facial stimuli processing. Genes Brain Behav 6:364-374

5. Biederman J, Faraone SV, Monuteaux MC (2002) Differential effect of environmental adversity by gender: Rutter's index of adversity in a group of boys and girls with and without ADHD. Am J Psychiatry 159:1556-1562

6. Blair C, Diamond A (2008) Biological processes in prevention and intervention: the promotion of self-regulation as a means of preventing school failure. Dev Psychopathol 20:899-911

7. Blasi G, Mattay VS, Bertolino A, Elvevåg B, Callicott JH, Das S, Kolachana BS, Egan MF, Goldberg TE, Weinberger DR (2005) Effect of catechol- $O$-methyltransferase val158met genotype on attentional control. J Neurosci 25:5038-5045

8. Burt SA, Krueger RF, McGue M, Iacono W (2003) Parent-child conflict and the comorbidity among childhood externalizing disorders. Arch Gen Psychiatry 60:505-513

9. Caspi A, Langley K, Milne B, Moffitt TE, O’Donovan M, Owen MJ, Polo Tomas M, Poulton R, Rutter M, Taylor A, Williams B, Thapar A (2008) A replicated molecular genetic basis for subtyping antisocial behavior in children with attention-deficit/ hyperactivity disorder. Arch Gen Psychiatry 65:203-210

10. Caspi A, McClay J, Moffitt TE, Mill J, Martin J, Craig IW, Taylor A, Poulton R (2002) Role of genotype in the cycle of violence in maltreated children. Science 297:851-854

11. Chen J, Lipska BK, Halim N, Ma QD, Matsumoto M, Melhem S, Kolachana BS, Hyde TM, Herman MM, Apud J, Egan MF, Kleinman JE, Weinberger DR (2004) Functional analysis of genetic variation in catechol-O-methyltransferase (COMT): effects on mRNA, protein, and enzyme activity in postmortem human brain. Am J Hum Genet 75:807-821

12. Cheuk DK, Wong V (2006) Meta-analysis of association between a catechol- $O$-methyltransferase gene polymorphism and attention deficit hyperactivity disorder. Behav Genet 36:651-659

13. Collett BR, Ohan JL, Myers KM (2003) Ten-year review of rating scales. VI: scales assessing externalizing behaviors. J Am Acad Child Adolesc Psychiatry 42:1143-1170

14. Conger RD, Wallace LE, Sun Y, Simons RL, McLoyd VC, Brody GH (2002) Economic pressure in African American families: a replication and extension of the family stress model. Dev Psychol 38:179-193

15. Diamond A (2007) Consequences of variations in genes that affect dopamine in prefrontal cortex. Cereb Cortex 17:161-170

16. Dodge KA, Pettit GS, Bates JE (1994) Socialization mediators of the relation between socioeconomic status and child conduct problems. Child Dev 65:649-665 
17. Eaves LJ (2006) Genotype $\times$ environment interaction in psychopathology: fact or artifact? Twin Res Hum Genet 9:1-8

18. Egan MF, Goldberg TE, Kolachana BS, Callicott JH, Mazzanti CM, Straub RE, Goldman D, Weinberger DR (2001) Effect of COMT Val108/158 Met genotype on frontal lobe function, risk for schizophrenia. Proc Natl Acad Sci USA 98:6917-6922

19. Egeland B (1997) Mediators of the effect of child maltreatment on developmental adaptation in adolescence. In: Cicchetti D, Toth SL (eds) Developmental perspectives on trauma: theory, research, and intervention. University of Rochester Press, Rochester, pp 403-434

20. Faraone SV, Perlis RH, Doyle AE, Smoller JW, Goralnick JJ, Holmgren MA, Sklar P (2005) Molecular genetics of attentiondeficit/hyperactivity disorder. Biol Psychiatry 57:1313-1323

21. Frigerio A, Cattaneo C, Cataldo MG, Schiatti A, Molteni M, Battaglia M (2004) Behavioral and emotional problems among Italian children and adolescents aged 4 to 18 years as reported by parents and teachers. Eur J Psychol Assess 20:124-133

22. Frigerio A, Vanzin L, Pastore V, Nobile M, Giorda R, Marino C, Molteni M, Rucci P, Ammaniti M, Lucarelli L, Lenti C, Walder M, Martinuzzi A, Carlet O, Muratori F, Milone A, Zuddas A, Cavolina P, Nardocci F, Tullini A, Morosini P, Polidori G, De Girolamo G (2006) The Italian preadolescent mental health project (PrISMA): rationale and methods. Int J Methods Psychiatr Res 15:22-35

23. Frigerio A, Rucci P, Goodman R, Ammaniti M, Carlet O, Cavolina P, De Girolamo G, Lenti C, Lucarelli L, Mani E, Martinuzzi A, Micali N, Milone A, Morosini P, Muratori F, Nardocci F, Pastore V, Polidori G, Tullini A, Vanzin L, Villa L, Walter M, Zuddas A, Molteni M (2009) Prevalence and correlates of mental disorders among adolescents in Italy: the PrISMA study. Eur Child Adolesc Psychiatry 18:217-226

24. Gallinat J, Bajbouj M, Sander T, Schlattmann P, Xu K, Ferro EF, Goldman D, Winterer G (2003) Association of the G1947A COMT (Val(108/158)Met) gene polymorphism with prefrontal P300 during information processing. Biol Psychiatry 54:40-48

25. Hariri AR, Weinberger DR (2003) Functional neuroimaging of genetic variation in serotonergic neurotransmission. Genes Brain Behav 2:341-349

26. Hollingshead AB (1975) Four factor index of social status. Yale University, Department of Sociology, New Haven, CT (unpublished manuscript)

27. Jaffee SR, Moffitt TE, Caspi A, Taylor A, Arseneault L (2002) Influence of adult domestic violence on children's internalizing and externalizing problems: an environmentally informative twin study. J Am Acad Child Adolesc Psychiatry 41:1095-1103

28. Karoum F, Chrapusta SJ, Egan MF (1994) 3-Methoxytyramine is the major metabolite of released dopamine in the rat frontal cortex: reassessment of the effects of antipsychotics on the dynamics of dopamine release and metabolism in the frontal cortex, nucleus accumbens, and striatum by a simple two pool model. J Neurochem 63:972-979

29. Keiley MK, Bates JE, Dodge KA, Pettit GS (2000) A crossdomain growth analysis: externalizing and internalizing behaviors during 8 years of childhood. J Abnorm Child Psychol 28:161-179

30. Krol NP, De Bruyn EE, Coolen JC, van Aarle EJ (2006) From CBCL to DSM: a comparison of two methods to screen for DSMIV diagnoses using CBCL data. J Clin Child Adolesc Psychol $35: 127-135$

31. Lambert MC, Knight F, Taylor R, Achenbach T (1994) Epidemiology of behavioral and emotional problems among children of Jamaica and the United States: parent reports for ages 6 to 11 . J Abnorm Child Psychol 22:113-128

32. Larsson B, Frisk M (1999) Social competence and emotional/ behavior problems in 6-16-year-old Swedish school children. Eur Child Adolesc Psychiatry 8:24-33
33. Lasky-Su J, Faraone SV, Lange C, Tsuang MT, Doyle AE, Smoller JW, Laird NM, Biederman J (2007) A study of how socioeconomic status moderates the relationship between SNPs encompassing BDNF and ADHD symptom counts in ADHD families. Behav Genet 37:487-497

34. Liu X, Kurita H, Guo C, Miyake Y, Ze J, Cao H (1999) Prevalence and risk factors of behavioral and emotional problems among Chinese children aged 6 through 11 years. J Am Acad Child Adolesc Psychiatry 38:708-715

35. Loeber R, Green SM, Keenan K, Lahey BB (1995) Which boys will fare worse? Early predictors of the onset of conduct disorder in a six-year longitudinal study. J Am Acad Child Adolesct Psychiatry 34:499-509

36. Lotta T, Vidgren J, Tilgmann C, Ulmanen I, Melén K, Julkunen I, Taskinen J (1995) Kinetics of human soluble and membranebound catechol O-methyltransferase: a revised mechanism and description of the thermolabile variant of the enzyme. Biochemistry $34: 4202-4210$

37. MacDonald VM, Tsiantis J, Achenbach TM, Motti-Stefanidi F, Richardson SC (1995) Competencies and problems reported by parents of Greek and American children, ages 6-11. Eur Child Adolesc Psychiatry 4:1-13

38. Manly JT, Kim JE, Rogosch FA, Cicchetti D (2001) Dimensions of child maltreatment and children's adjustment: contributions of developmental timing and subtype. Dev Psychopathol 13:759782

39. Mattay VS, Goldberg TE, Fera F, Hariri AR, Tessitore A, Egan MF, Kolachana B, Callicott JH, Weinberger DR (2003) Catechol O-methyltransferase val158-met genotype and individual variation in the brain response to amphetamine. Proc Natl Acad Sci USA 100:6186-6191

40. Mick E, Biederman J, Prince J, Fischer MJ, Faraone SV (2002) Impact of low birth weight on attention-deficit hyperactivity disorder. J Dev Behav Pediatr 23:16-22

41. Nobile M, Giorda R, Marino C, Carlet O, Pastore V, Vanzin L, Bellina M, Molteni M, Battaglia M (2007) Socioeconomic status mediates the genetic contribution of the dopamine receptor D4 and serotonin transporter linked promoter region repeat polymorphisms to externalization in preadolescence. Dev Psychopathol 19:1147-1160

42. Nobile M, Rusconi M, Bellina M, Marino C, Giorda R, Carnet O, Vanzin L, Molteni M, Battaglia M (2009) TPH2 G-703T and the 5-HTTLPR serotonergic genes upon affective problems in children aged 10-14 years. J Child Psychol Psychiatry 50:317-325

43. Novik TS (1999) Validity of the child behavior checklist in a Norwegian sample. Eur Child Adolesc Psychiatry 8:247-254

44. Roussos A, Karantanos G, Richardson C, Hartman C, Karajiannis D, Kyprianos S, Lazaratou H, Mahaira O, Tassi M, Zoubou V (1999) Achenbach's child behavior checklist and teacher's report form in a normative sample of Greek children 6-12 years old. Eur Child Adolesc Psychiatry 8:165-172

45. Rutter M, Moffitt TE, Caspi A (2006) Gene-environment interplay and psychopathology: multiple varieties but real effects. J Child Psychol Psychiatry 47:226-261

46. Sengupta SM, Grizenko N, Schmitz N, Schwartz G, Ben Amor L, Bellingham J, de Guzman R, Polotskaia A, Ter Stepanian M, Thakur G, Joober R (2006) COMT Val108/158Met gene variant, birth weight, and conduct disorder in children with ADHD. J Am Acad Child Adolesc Psychiatry 45:1363-1369

47. Smolka MN, Schumann G, Wrase J, Grüsser SM, Flor H, Mann $\mathrm{K}$, Braus DF, Goldman D, Büchel C, Heinz A (2005) Catechol- $O$ methyltransferase val158met genotype affects processing of emotional stimuli in the amygdala and prefrontal cortex. J Neurosci 25:836-842

48. Spatola CA, Fagnani C, Pesenti-Gritti P, Ogliari A, Stazi MA, Battaglia M (2007) A general population twin study of the 
CBCL/6-18 DSM-oriented scales. J Am Acad Child Adolesc Psychiatry 46:619-627

49. Spielman RS, Weinshilboum RM (1981) Genetics of red cell COMT activity: analysis of thermal stability and family data. Am J Med Genet 10:279-290

50. Steinhausen HC, Winkler Metzke C, Meier M, Kannenberg R (1997) Behavioral and emotional problems reported by parents for ages 6 to 17 in a Swiss epidemiological study. Eur Child Adolesc Psychiatry 6:136-141

51. Thapar A, Langley K, Fowler T, Rice F, Turic D, Whittinger N, Aggleton J, Van den Bree M, Owen M, O’Donovan M (2005) Catechol $O$-methyltransferase gene variant and birth weight predict early-onset antisocial behavior in children with attentiondeficit/hyperactivity disorder. Arch Gen Psychiatry 62:12751278

52. Wadsworth ME, Achenbach TM (2005) Explaining the link between low socioeconomic status and psychopathology: testing two mechanisms of the social causation hypothesis. J Consult Clin Psychol 73:1146-1153

53. Wahlstrom D, White T, Hooper CJ, Vrshek-Schallhorn S, Oetting WS, Brott MJ, Luciana M (2007) Variations in the catechol Omethyltransferase polymorphism and prefrontally guided behaviors in adolescents. Biol Psychiatry 61:626-632 